\title{
Safety studies and viral shedding of intramuscular administration of oncolytic vaccinia virus TG6002 in healthy beagle dogs
}

Jérémy Béguin ${ }^{1,2,3^{*}} \mathbb{D}$, Virginie Nourtier ${ }^{1}$, Murielle Gantzer ${ }^{1}$, Sandrine Cochin ${ }^{1}$, Johann Foloppe ${ }^{1}$, Jean-Marc Balloul ${ }^{1}$, Eve Laloy ${ }^{2,4}$, Dominique Tierny ${ }^{5}$, Bernard Klonjkowski ${ }^{2}$, Eric Quemeneur ${ }^{1}$, Christelle Maurey ${ }^{3}$ and Philippe Erbs ${ }^{1}$

\begin{abstract}
Background: Cancer is a leading cause of mortality for both humans and dogs. As spontaneous canine cancers appear to be relevant models of human cancers, developing new therapeutic approaches could benefit both species. Oncolytic virotherapy is a promising therapeutic approach in cancer treatment. TG6002 is a recombinant oncolytic vaccinia virus deleted in the thymidine kinase and ribonucleotide reductase genes and armed with the suicide gene FCU1 that encodes a protein which catalyses the conversion of the non-toxic 5-fluorocytosine into the toxic metabolite 5-fluorouracil. Previous studies have shown the ability of TG6002 to infect and replicate in canine tumor cell lines, and demonstrated its oncolytic potency in cell lines, xenograft models and canine mammary adenocarcinoma explants. Moreover, 5 -fluorouracil synthesis has been confirmed in fresh canine mammary adenocarcinoma explants infected with TG6002 with 5-fluorocytosine. This study aims at assessing the safety profile and viral shedding after unique or repeated intramuscular injections of TG6002 in seven healthy Beagle dogs.

Results: Repeated intramuscular administrations of TG6002 at the dose of $5 \times 10^{7} \mathrm{PFU} / \mathrm{kg}$ resulted in no clinical or biological adverse effects. Residual TG6002 in blood, saliva, urine and feces of treated dogs was not detected by infectious titer assay nor by qPCR, ensuring the safety of the virus in the dogs and their environment.

Conclusions: These results establish the good tolerability of TG6002 in healthy dogs with undetectable viral shedding after multiple injections. This study supports the initiation of further studies in canine cancer patients to evaluate the oncolytic potential of TG6002 and provides critical data for clinical development of TG6002 as a human cancer therapy.
\end{abstract}

Keywords: Oncolytic virotherapy, Vaccinia virus, TG6002, FCU1, Cancer, Safety, Canine, Translational research

\footnotetext{
* Correspondence: jeremy.beguin@vet-alfort.fr

${ }^{1}$ Transgene, Illkirch-Graffenstaden, France

${ }^{2}$ UMR Virologie, INRAE, Ecole Nationale Vétérinaire d'Alfort, ANSES, Université

Paris-Est, Maisons-Alfort, France

Full list of author information is available at the end of the article
}

(c) The Author(s). 2020 Open Access This article is licensed under a Creative Commons Attribution 4.0 International License, which permits use, sharing, adaptation, distribution and reproduction in any medium or format, as long as you give appropriate credit to the original author(s) and the source, provide a link to the Creative Commons licence, and indicate if changes were made. The images or other third party material in this article are included in the article's Creative Commons licence, unless indicated otherwise in a credit line to the material. If material is not included in the article's Creative Commons licence and your intended use is not permitted by statutory regulation or exceeds the permitted use, you will need to obtain permission directly from the copyright holder. To view a copy of this licence, visit http://creativecommons.org/licenses/by/4.0/ The Creative Commons Public Domain Dedication waiver (http://creativecommons.org/publicdomain/zero/1.0/) applies to the data made available in this article, unless otherwise stated in a credit line to the data. 


\section{Background}

Cancer is a leading cause of mortality throughout the world for both humans and dogs. The incidence of cancer ranges from 1 to $2 \%$ in the canine population and accounts for about half of the deaths in dogs older than 10 years [1, 2]. Despite progress in the diagnosis and treatment of advanced canine cancers, complete longlasting remissions are still infrequent. Therefore, new therapeutic approaches are needed.

The use of oncolytic viruses to treat cancer is an emerging field in cancer research and therapy. Oncolytic virotherapy is a promising therapeutic option based on the ability of engineered viral vectors to selectively replicate in cancer cells leading to their lysis and to deliver genes encoding therapeutic proteins into cancer cells [3]. Many viruses have been studied in preclinical and clinical studies, including adenovirus, vaccinia virus, herpes virus, parvovirus, picornavirus and reovirus in both human and veterinary medicine [4-6]. Vaccinia virus (VACV) is a large, double stranded DNA virus, and member of the poxviridae family. Its ability to efficiently replicate, lyse host cells, and evade immune responses make VACV an attractive candidate for human and veterinary oncolytic virotherapy [7]. VACV has been shown to replicate and lyse tumor cells within $72 \mathrm{~h}$ of infection [8]. Furthermore, VACV replicates in cell cytoplasm, preventing the integration of viral DNA into host chromosomes [9]. VACV has also been shown to exhibit broad tumor tropism [8]. In human medicine, Pexa-Vec (pexastimogene devacirepvec, JX-594, SillaJen Biotherapeutics, Seoul, South Korea) is the most advanced VACV oncolytic product. It is derived from a VACV strain engineered to express GM-CSF and has successfully entered Phase III clinical trials [10]. An oncolytic VACV, designated as TG6002, has been developed with deletion of the thymidine kinase $(T K)$ and the ribonucleotide reductase $(R R)$ loci in its genome resulting in attenuated virulence and enhanced tumor-specific targeting [11]. To enhance therapeutic efficacy, the chimeric gene FCU1 was inserted in the TG6002 genome. FCU1 encodes a bifunctional fusion protein combining cytosine deaminase and uracil phosphoribosyltransferase activities. FCU1 converts the non-toxic prodrug 5-fluorocytosine (5-FC) into the chemotherapeutic compound 5-fluorouracil (5FU), and further into 5-fluorouracil-monophosphate, which inhibits DNA and protein synthesis [12]. In murine xenograft mice treated by TG6002 followed by per os 5-FC administration, high levels of 5-FU were detected in tumors [11]. In this model, TG6002 in combination with 5-FC has significant antitumor efficacy against a large range of human tumors [11]. Another study has also showed relevant oncolytic features of TG6002 as an oncolytic therapy on canine cancer cell lines, mouse xenografts and canine mammary tumor explants [13]. Intratumoral injections of TG6002 in canine mammary tumor cells grafted onto mice lead to a significant decrease in tumor size [13]. Administration of 5-FC to those mice significantly improved the antitumor activity of TG6002. Finally, canine mammary tumor explants cultured with TG6002 and 5-FC, allowed the assessment of tumor necrosis, and conversion of 5-FC into 5-FU [13].

Evaluation of TG6002 in cancer-bearing dogs could be beneficial for both humans and dogs. As spontaneous canine tumors are relevant models for translational research in oncology, they can provide useful preclinical data for human medicine [14-16]. Moreover, new therapeutic strategies are needed to improve therapeutic options in veterinary medicine. Biosafety is a major issue with oncolytic viruses for both patients and the environment. VACV infection is generally associated with cutaneous pock lesions which participate in the shedding of the virus [17]. Clinical trials using attenuated oncolytic VACV in patients diagnosed with cancer have reported the development of mucocutaneous pustules after treatment [10, 18-23]. Similar lesions have been described in dogs receiving a TK-deleted VACV [24]. VACV is known to remain detectable in urine and feces for a long time [25-27]. Thus, before the use of TG6002 in pet dogs, evaluations of safety and viral shedding are needed. Considering the promising results obtained by the intratumoral route on xenograft models, intramuscular injections were chosen to mimic this route of administration in healthy dogs.

The present study aims at assessing the tolerability and viral shedding following intramuscular injections of escalating doses of TG6002 in healthy dogs. This study is a prerequisite for a phase 1 trial of intratumoral delivery of TG6002 in pet dogs suffering from incurable cancers.

\section{Results \\ Single intramuscular injection of TG6002 was well tolerated in four healthy dogs}

During the single injection phase, only a decrease in body weight scored as grade 1 was recorded for all dogs (Fig. 1a). The median percentage value of maximal weight loss was $6.05 \%$. The decrease in body weight did not seem related to the viral titer. Only one dog (Dog 1 treated with $1 \times 10^{6} \mathrm{PFU} / \mathrm{kg}$ of TG6002) had a transient increase in temperature $\left(39.4{ }^{\circ} \mathrm{C}\right.$, grade 1) 7 days after TG6002 administration (Fig. 1b). Hyperthermia was not seen in the other dogs. Furthermore, no mucocutaneous or skin lesions at the injection site, nor any other clinical abnormalities were found. In addition, hematological and biochemical analyses performed on day 14 did not reveal toxicity (Fig. 2) [see Additional file 1]. For Dog 2, treated with $5 \times 10^{6} \mathrm{PFU} / \mathrm{kg}$ of TG6002, total proteins 


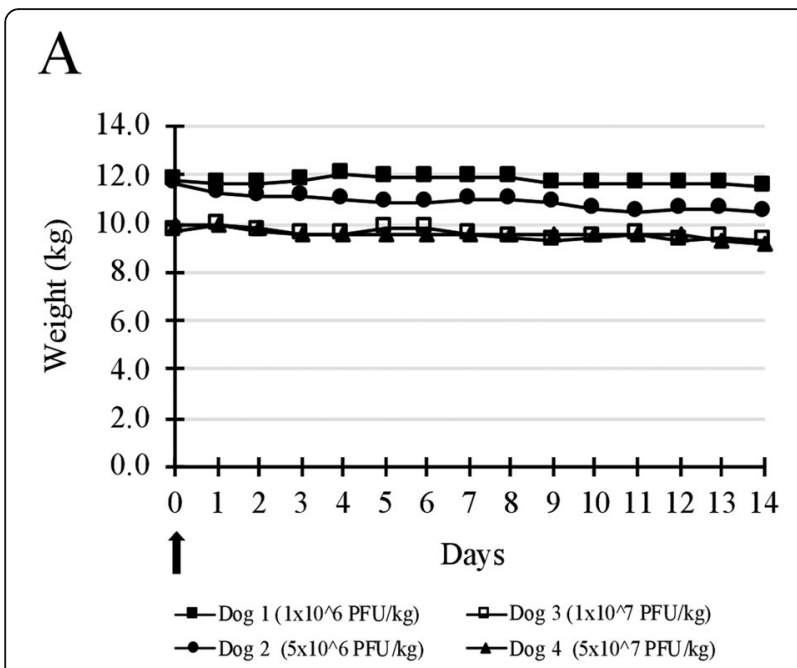

B

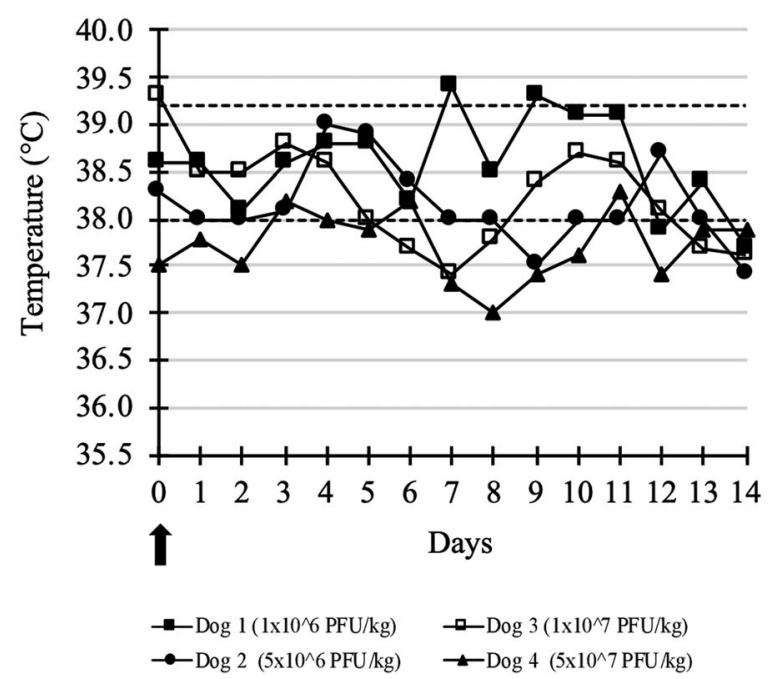

Fig. 1 Weight (a) and temperature (b) of dogs after a single intramuscular injection of TG6002. No significant change in the weight and temperature of dogs was noticed after a single intramuscular injection of TG6002. Arrows indicate TG6002 administrations. Dotted lines represent the reference interval

were stable but in the lower part of the reference interval at days 0 and 14. For Dog 3, treated with $1 \times 10^{7} \mathrm{PFU} / \mathrm{kg}$ of TG6002, a moderate decrease of total proteins was noticed between day 0 and 14 [see Additional file 1]. As maximal tolerated dose (MTD) was not reached, the highest tested dose of $5 \times 10^{7} \mathrm{PFU} / \mathrm{kg}$ was selected for administration in the second phase of the study.

\section{Repeated intramuscular injections of $5 \times 10^{7} \mathrm{PFU} / \mathrm{kg}$ of} TG6002 with oral 5-FC administration were well tolerated in three healthy dogs

During the repeated injections phase, only a decrease in body weight scored as grade 1 was observed in two dogs
(Fig. 3a). The median percentage value of maximal weight loss was $7.89 \%$. No hyperthermia was observed (Fig. 3b). Neither mucocutaneous nor skin lesions at the injection site, nor other clinical abnormalities were found. For all dogs, an increase in the white blood cell count was noticed at days 9 and 21 (Fig. 4). On day sixteen even with values within the reference interval, a decrease in white blood cell count was noticed in all dogs. (Fig. 4). No significant abnormalities were seen in the biochemical analytes reference intervals for all dogs [see Additional file 2].

Dog 7 showed lethargy (grade 1), anorexia (grade 3), vomiting (grade 2), diarrhea (grade 2), transient melena (grade 2) and decreased body weight (grade 2) 1 day after the third injection. Analysis of serum biochemistry values revealed an increase in blood urea nitrogen (BUN) (12.70 $\mathrm{mmol} / \mathrm{L}$; reference interval: 3.30 to $10.00 \mathrm{mmol} / \mathrm{L}$ ) (grade 2) with normal creatinemia $(51.00 \mu \mathrm{mol} / \mathrm{L}$; reference interval: 36.00 to $106.00 \mu \mathrm{mol} / \mathrm{L}$ ) and a slight increase in alkaline phosphatase (158 UI/L; reference interval: 29 to 153 UI/L) [see Additional file 2]. No hematological abnormalities were observed (Fig. 4). Abdominal ultrasound examination was normal. Supportive care consisting of gastrointestinal protectants, a histamine type- 2 receptor antagonist and supportive diet was initiated for the digestive disorders. Oral administration of kaolin and pectin (Kaopectate, Zoetis, Malakoff, France) $5 \mathrm{ml}$ twice daily and sucralfate (Ulcar, Sanofi-Aventis, Gentilly, France) $1 \mathrm{~g}$ three times a day, with intravenous injections of ranitidine (Azantac, Laboratoire Glaxosmithkline, Marly-le-Roi, France) $1 \mathrm{mg} / \mathrm{kg}$ twice daily were dispensed. As melena was seen, an associated risk for bacterial translocation was determined, enrofloxacin (Xeden, CEVA santé Animale, Libourne, France) $5 \mathrm{mg} / \mathrm{kg}$ once daily per os was administered. Four days later, a complete resolution of clinical signs was seen and treatments were stopped at day 22. A progressive weight recovery was also observed until the thirty-fifth day. To evaluate histopathological abnormalities and viral shedding, euthanasia under general anesthesia was elected for Dog 7. Anesthesia was performed using an initial intravenous administration of $0.2 \mathrm{mg} / \mathrm{kg}$ of butorphanol (Torbugesic, Zoetis, Malakoff, France), $3 \mathrm{mg} / \mathrm{kg}$ of ketamine (Ketamine 1000, Virbac, Carros, France) and $15 \mu \mathrm{g} / \mathrm{kg}$ of medetomidine (Domitor, Orion Corporation, Espoo, Finland). After the dog was sedated, an intravenous injection of $180 \mathrm{mg} / \mathrm{kg}$ of sodium pentobarbital solution (Dolethal, Vetoquinol, Magny Vernois, France) was given. Postmortem examination revealed no relevant pathological changes, especially in the digestive tract, liver and kidneys. Histological analyses only revealed a slight degenerative renal tubulopathy with intra-epithelial pigment, a generalized vacuolar hepatopathy and a slight diffuse necrotic hepatitis. Immunohistochemical analyses of kidney and liver samples using VACV antibody were negative. 


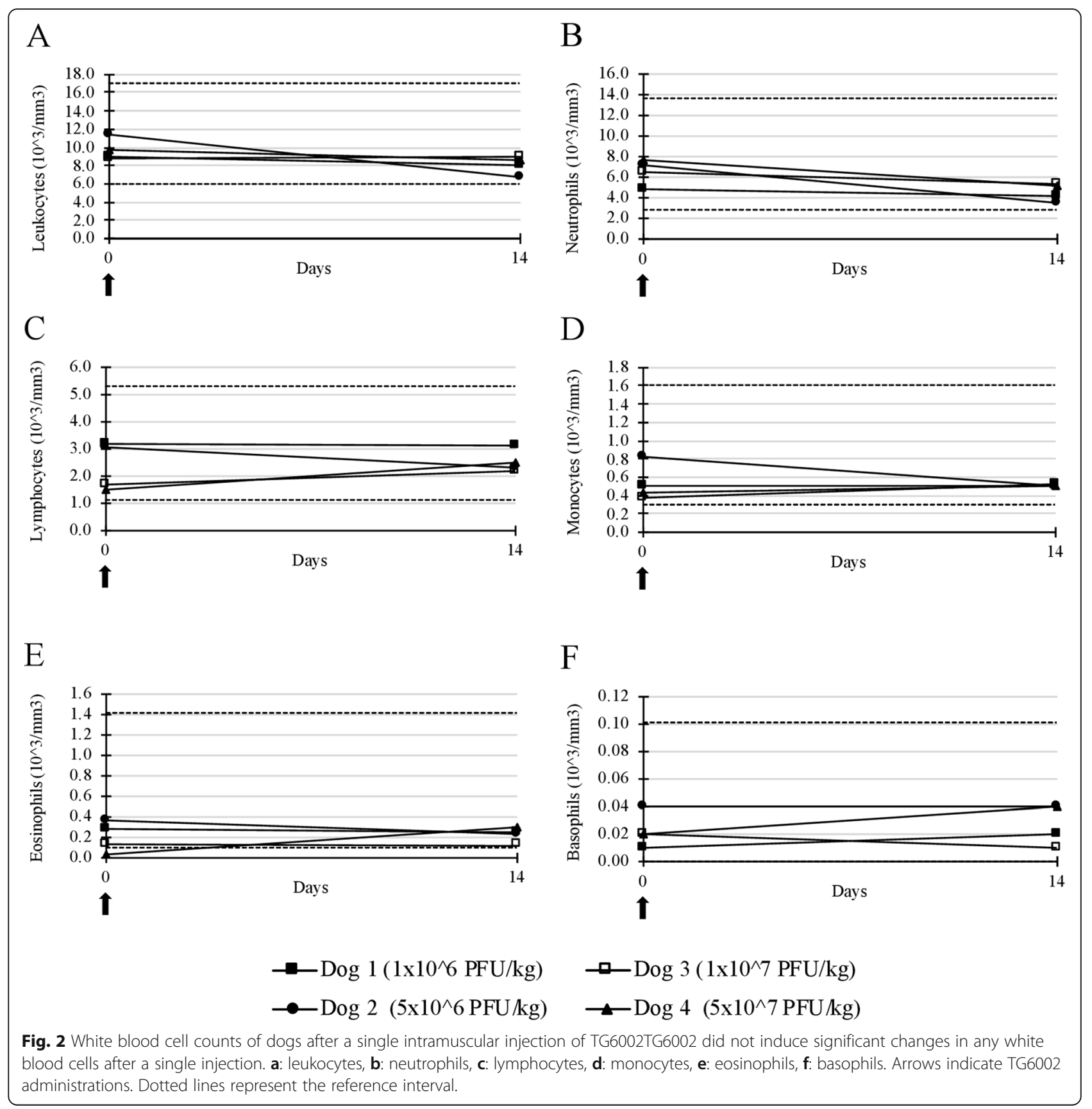

Infectious VACV was not detected in blood, urine and saliva Residual TG6002 was assessed by quantification of the infectious titer on chicken embryo fibroblasts (CEF) by plaque assay. No infectious virus was detected in blood and biological samples of treated dogs after virus administration for both parts of the study [see Additional file 3] [see Additional file 4].

VACV DNA was not detected in blood, urine, feces and saliva Viral DNA was not detected in blood, urine, feces, and saliva by qPCR assay for both parts of the study [see
Additional file 5] [see Additional file 6]. All samples gave results below the limit of detection of the assay.

\section{Discussion}

Oncolytic viruses are gaining ground as an alternative therapy in veterinary oncology. Several studies involving adenovirus, myxoma virus, Sendai virus, reovirus and vesicular stomatitis virus have been conducted in dogs and cats [28-36]. Promising results have been reported by intratumoral or intravenous routes on dogs and cats with cancer. No study has yet evaluated an oncolytic 


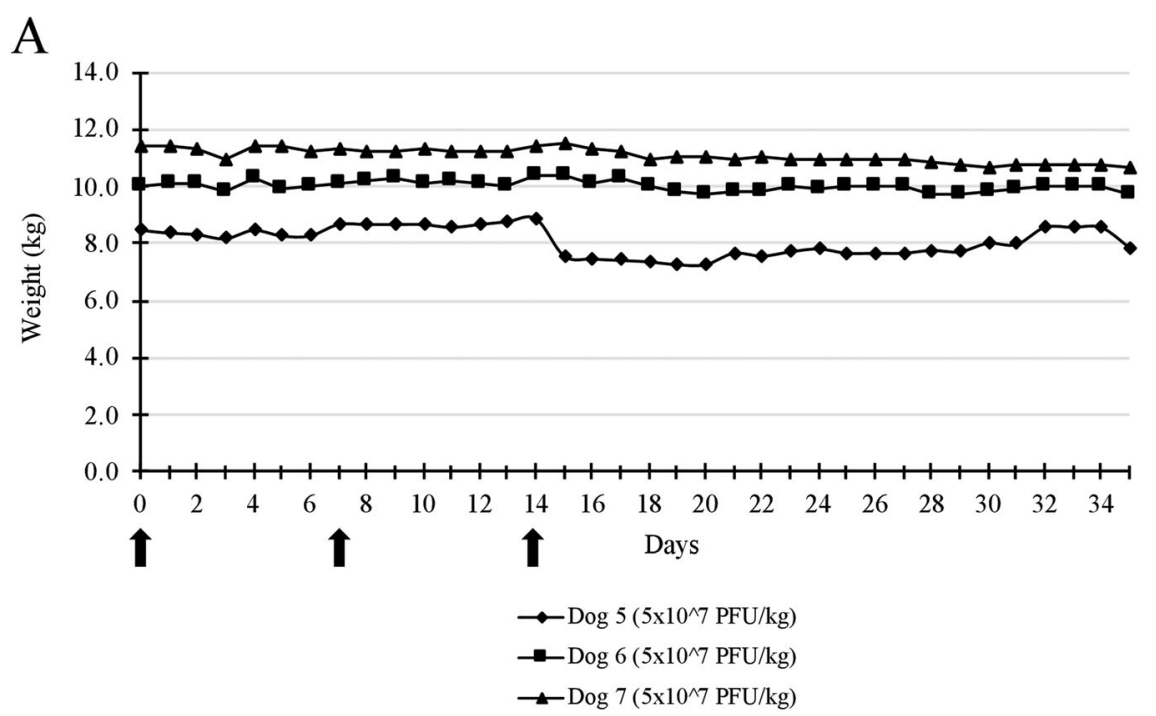

B

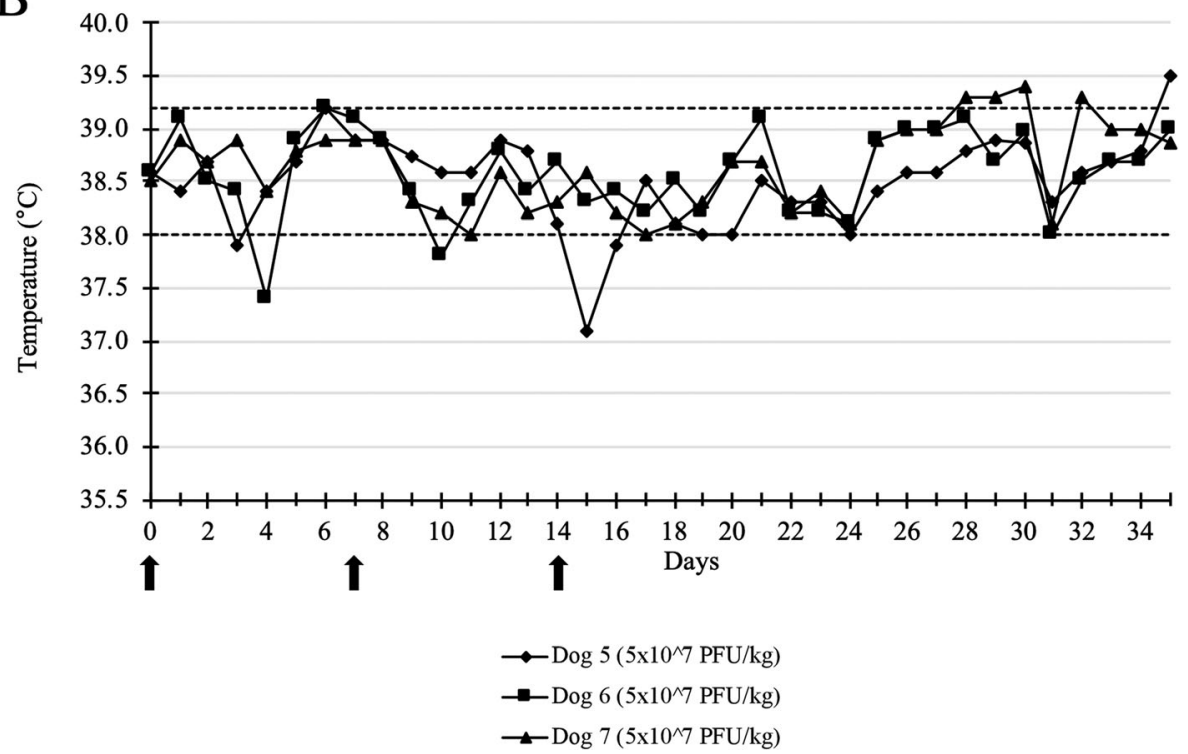

Fig. 3 Weight (a) and temperature (b) of dogs after three intramuscular injections of TG6002. No significant change in the weight and temperature of dogs was noticed after repeated intramuscular injections of TG6002 at $5 \times 10^{7}$ PFU/kg. Arrows indicate TG6002 administrations. Dotted lines represent the reference interval

VACV allowing intratumoral production of a chemotherapy drug. Our study describes the dose, clinical toxicities and viral shedding after intramuscular administration of TG6002 with oral 5-FC in seven healthy immune-competent dogs. As TG6002 is engineered from VACV, evaluating both the safety and the shedding profiles of this attenuated virus remains essential. Thus, to provide more reliable information on tolerance, seven healthy dogs with a competent immune system were selected for this study. Due to ethical concerns, safety studies evaluating oncolytic viruses only involve small numbers of healthy animals [37-40]. Considering the low number of dogs in our study, it is important to remain cautious about the absence of major toxicities.

Data collected in this preclinical study on seven dogs indicate that administration of TG6002 was well tolerated in all dogs. MTD was not reached even at the highest tested dose of $5 \times 10^{7} \mathrm{PFU} / \mathrm{kg}$. Only transient weight loss for all dogs and digestive disorders for one dog out of seven were observed. One transient history of hyperthermia was noticed for one dog out of seven receiving TG6002 at the lowest dosage. During the second part of the study, a decrease in the white blood cell count was observed on day 16 for all dogs. Hematological changes were transient and values remained within the reference 

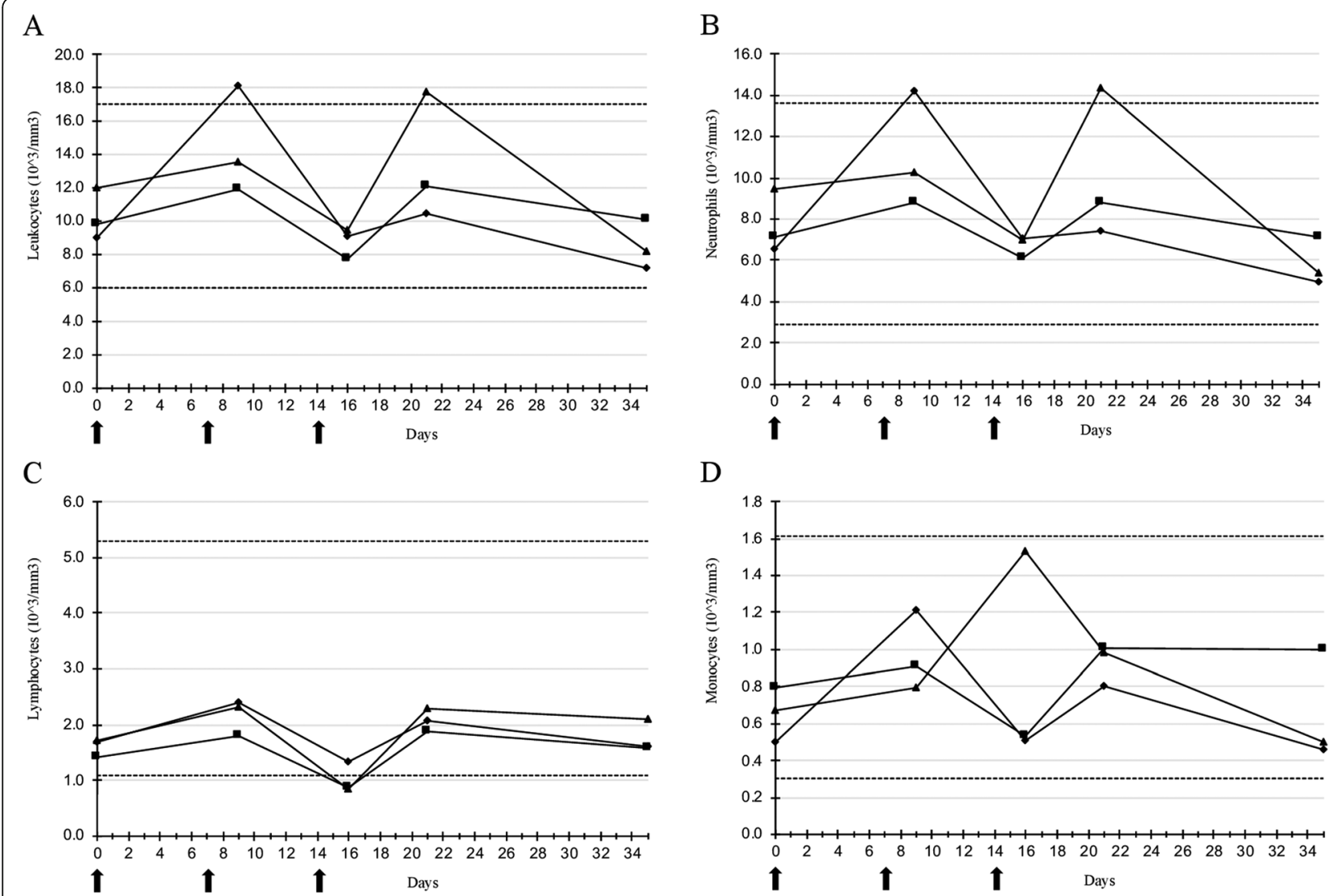

D

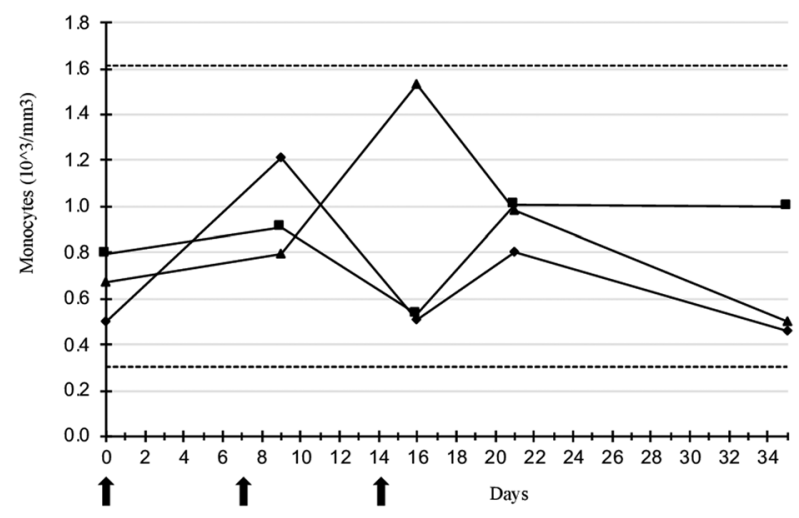

$\mathrm{E}$
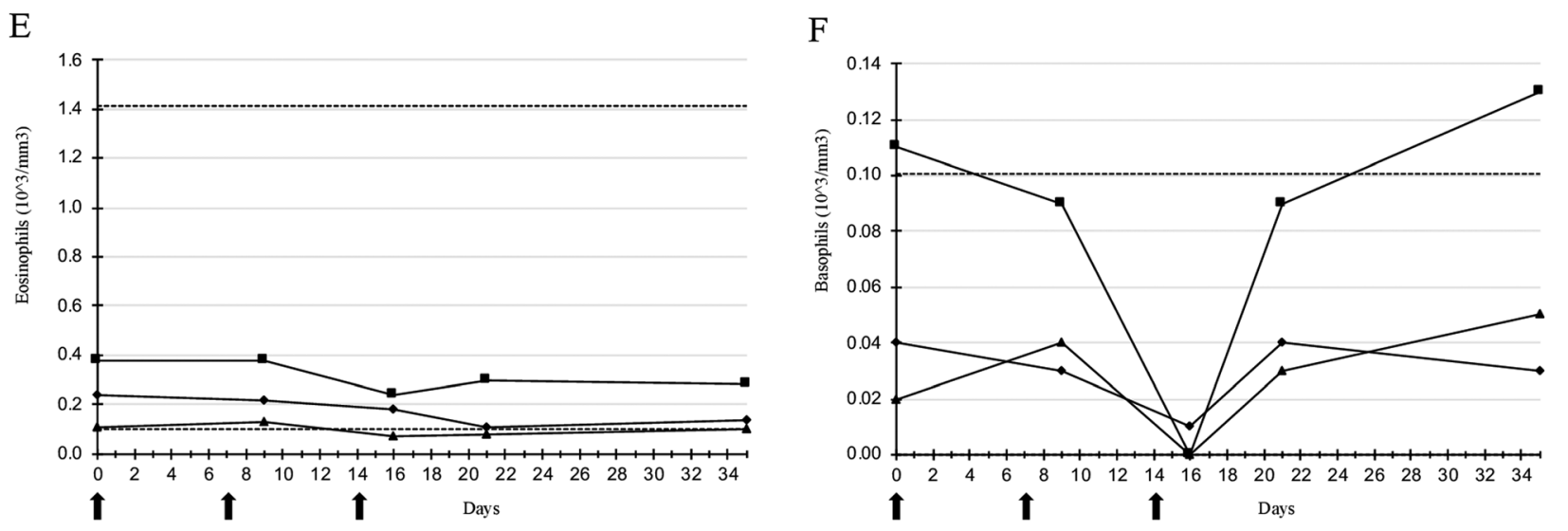

\section{$\rightarrow-\operatorname{Dog} 5\left(5 \times 10^{\wedge} 7 \mathrm{PFU} / \mathrm{kg}\right)$ \\ $\rightarrow-\operatorname{Dog} 6\left(5 \times 10^{\wedge} 7 \mathrm{PFU} / \mathrm{kg}\right)$ \\ $\multimap \operatorname{Dog} 7\left(5 \times 10^{\wedge} 7 \mathrm{PFU} / \mathrm{kg}\right)$}

Fig. 4 White blood cell counts of dogs after three intramuscular injections of TG6002. TG6002 did not induce significant changes in any white blood cells after repeated injections of TG6002 at $5 \times 10^{7}$ PFU/kg. a: leukocytes, b: neutrophils, c: lymphocytes, d: monocytes, e: eosinophils, $\mathbf{f}$ : basophils. Arrows indicate TG6002 administrations. Dotted lines represent the reference interval

intervals. For all dogs $(n=3)$ receiving three injections of TG6002, increases of neutrophil, lymphocyte and monocyte counts were noticed after the second injection. An inflammatory response secondary to VACV injection was suspected. After the third injection, decreases of neutrophil, lymphocyte, monocyte, eosinophil and basophil counts were observed. Even if a stress response could not be excluded, hematological changes were 
suspected to be induced by viral injection. Similar variations have been described in laboratory beagles receiving intravenous administrations of an oncolytic VACV encoding CD40 ligand [37]. Leukopenia has also been reported in human trials with intratumoral oncolytic VACV. In an intratumoral dose escalation clinical trial using a Western Reserve Strain Oncolytic VACV only a grade 1or 2 leukopenia was reported in one human patient out of $16(6.3 \%)$ treated with $1 \times 10^{9} \mathrm{PFU}$ [41]. In pediatric cancer patients, only a grade 3 lymphopenia was reported in one patient out of seven receiving intratumoral injection of Pexa-Vec at $1 \times 10^{7} \mathrm{PFU} / \mathrm{kg}$ [42]. However, as 5-FU can induce bone marrow depression, it would have been interesting to evaluate serum concentrations of 5-FU in our study.

Other adverse events reported in laboratory beagles, receiving intravenous administration of an oncolytic VACV encoding CD40 ligand, included transient grade 1 fever $(n=1 / 2)$ and grade 3 seizure $(n=1 / 2)$ [37]. Additionally, only a grade 1 increase in alkaline phosphatase $(n=1 / 2)$ and a mild decrease in albumin concentration (grade 1 ) $(n=1 / 2)$ were noticed without hematological or urine abnormalities [37]. In human trials adverse events secondary to intratumoral or intravenous administration of oncolytic VACV included fever, rigors, abdominal pain, nausea, vomiting, tiredness and headache $[19,20,42]$.

Infection with VACV is generally characterized by the development of cutaneous and mucocutaneous pock lesions [17]. Human cancer patients receiving attenuated oncolytic VACV have been reported to develop these lesions $[10,19,21,22]$. Safety of a TK-deleted VACV (VTK-79) administered by intradermal, subcutaneous or intranasal routes has been reported in laboratory beagles [24]. Only intradermal injections of $10^{7}$ PFU of VTK-79 have been reported to induce the development of small nodules at the site of inoculation [24]. However, no pock lesions were observed throughout our study even if dosages were greater than $10^{7} \mathrm{PFU}$. Deletions of both $T K$ and $R R$ genes have been shown to improve the safety profile of VACV, due to its high attenuation in normal tissues, compared to a single deleted oncolytic vector [11]. As VACV has a tropism for cutaneous and mucocutaneous tissues, the intramuscular route of administration could also explain the lack of pock lesions.

TG6002 has a tumor-selective viral replication induced by the double TK-RR deletion of the TG6002 genome and does not display pathogenic effects in normal tissue [11]. No pock lesions nor any other major clinical abnormalities were observed in our study. The lack of clinical adverse events confirms the safety profile of TG6002. However, the use of healthy dogs in our study could have limited the assessment of adverse events. The dogs in this study were cancer free, but in dogs with tumors the viral load could be higher and allow viral amplification. Thus, further studies of tolerance and viral shedding must be performed in dogs with cancer.

In our study, the transient mild weight loss seen in all dogs could have been induced by virus administration. Weight loss was observed for all dogs receiving TG6002 alone $(n=4)$ or with 5 -FC $(n=3)$. One dog (Dog 7) developed gastrointestinal signs which are likely related to 5-FC or TG6002. 5-FC is an antifungal agent, mainly used against strains of Cryptococcus and Candida. 5-FC penetrates fungal cells where it is deaminated by cytosine deaminase to 5 -FU. It acts as an antimetabolite by competing with uracil, thereby interfering with pyrimidine metabolism and eventually RNA and protein synthesis. It is thought that 5-FU is converted into 5-fluoro2 '-deoxyuridylate which inhibits thymidylate synthesis and ultimately DNA synthesis. In humans, 5-FC is rapidly absorbed with a bioavailability of $76-89 \%$ [43]. It penetrates well into most body sites and is mostly eliminated by glomerular filtration with a 3 to $4 \mathrm{~h}$ half-life $[44,45]$. A dose-dependent bone marrow depression (anemia, leukopenia, thrombocytopenia) and an increase in hepatic enzymes are reported [46]. Adverse events reported in dogs also include toxic epidermal necrolysis of the scrotum, nasal planum, lips and eyelids [47, 48]. These cutaneous adverse events resolve with discontinuation of 5-FC [47]. No cutaneous lesions nor hematological disorders induced by 5 -FC were observed in our study. In human medicine, blood concentration should not exceed $100 \mathrm{mg} / \mathrm{L}$ within $72 \mathrm{~h}$ of administration of 5-FC [49]. Thus, it would have been interesting to evaluate serum concentrations of $5-\mathrm{FC}$ and $5-\mathrm{FU}$ in our dogs. Studies suggest that 5 -FC can be converted into cytotoxic 5 -FU by intestinal microorganisms leading to intestinal disorders $[50,51]$. Due to the potential intestinal conversion of 5-FC into 5-FU, the dosage of 5$\mathrm{FU}$ in the feces and blood would have been interesting. In a phase 1 human trial, grade 1 or 2 nausea $(n=6 / 16$, $37.5 \%)$, grade 1 or 2 vomiting $(n=2 / 12 ; 12.5 \%)$, grade 1 or 2 diarrhea $(n=2 / 16,12.5 \%)$ and grade 3 gastrointestinal hemorrhage $(n=1 / 16 ; 6.3 \%)$ were reported after intratumoral injections of oncolytic VACV [41]. For Dog 7 , only an increase of BUN was noticed on biochemical analysis which was suggestive of dehydration or gastrointestinal bleeding. Post mortem examination did not reveal bowel lesions causing gastrointestinal bleeding. Even if no macroscopic intestinal lesions were observed during the necropsy, qPCR assay as well as histological and immunohistochemical analyses, would have been interesting to identify the causes of the gastrointestinal disorders.

Viral shedding detection is also important in the environmental risk assessment for this novel therapy. Viral shedding has been evaluated in dogs after intradermal or subcutaneous or intranasal administration of the TK- 
deleted VACV (VTK-79) [24]. Even if dogs with induced pock lesions were in close contact with sentinel dogs, none of these control animals developed VACV antibodies, which suggested the absence of viral shedding [24]. In a study with intravenous oncolytic VACV administrations in healthy dogs, the viral load, detected by qPCR, declined quickly in blood samples during the $4 \mathrm{~h}$ after infusion and viral DNA was not detected in feces, saliva and urine samples collected at 1,2, or 4 days after virus administration [37]. In human clinical trials, viral genome has also been detected in patients' blood after intratumoral administration of oncolytic VACV $[19,52]$. In the present study, neither infectious virus nor viral genome copies were detectable in blood, urine, saliva and feces. The absence of viral shedding can be explained by the characteristics of the viral vector and the route of administration. Due to the deletion of $T K$ and $R R$ genes, the virus can only replicate in dividing cells [11]. Intramuscular administration of viral vector in healthy dogs was not expected to be associated with replication of the vector. As TG6002 was designed for intratumoral injection, this administration route might promote vector replication in tumors. Thus, viral burden would likely be higher in dogs with tumors that allow viral amplification. Viral replication leads to the production of FCU1 protein and the conversion of 5-FC to 5FU. Expression of exogenous proteins without replication of the virus is considered negligible. Thus, 5-FU production was not expected after intramuscular injections in healthy dogs. In this context, tolerance and viral shedding must be evaluated further on dogs with cancer.

Previous studies evaluating oncolytic potency of TG6002 in cell lines and xenograft models have shown promising results $[11,13]$. However, murine xenograft models have limitations including an impaired immune system, tumor size and the non-spontaneous origin of the tumor. Highly relevant animal models are needed to assess the efficacy of treatment before human trials. In contrast to rodents, cancers arising in dogs have several commonalities with human cancers. Dogs share the same environment as their owners, their immune system is intact, and cancer progression is spontaneous resulting in similar complexity, clonality, and immune suppression as seen in man [53]. In addition, the same cancerassociated genes and histological features have been found in both species for several cancers such as urothelial carcinoma or mammary carcinoma $[54,55]$. It is now well recognized that dogs with spontaneous cancer serve as a good model for several human cancers [56]. One study has already established the oncolytic potency of TG6002 with 5-FC in canine mammary tumor explants [13]. Histological analyses of ex vivo canine mammary adenocarcinoma explants cultured with TG6002 and 5-FC, allowed assessment of tumor necrosis and conversion of 5-FC into 5-FU [13]. Considering dogs as a relevant model in oncology, and the promising in vitro results combined with the safety profile of TG6002 observed in the seven dogs in this study, intratumoral injections of $5 \times 10^{7} \mathrm{pfu} / \mathrm{kg}$ of TG6002 can be considered for clinical trial in dogs with spontaneous tumors. Individual dogs will benefit from effective treatment and the results are expected to help other dogs. Furthermore, the findings are expected to help in human oncology treatments.

\section{Conclusion}

Intramuscular injections of TG6002 at $5 \times 10^{7} \mathrm{PFU} / \mathrm{kg}$ with concurrent administrations of 5-FC was well tolerated in seven healthy dogs. The evaluation of viral shedding did not reveal TG6002 excretion in the environment. These results support the future evaluation of TG6002 in pet dogs with spontaneous tumors. A veterinary study will also provide critical data for the clinical development of TG6002 as a human cancer therapy. This translational approach fits well with the "One Health - One Medicine" concept and may contribute to the development of new therapies for animal and human cancers.

\section{Methods \\ Viral vector}

TG6002 was derived from the Copenhagen strain of VACV with targeted deletions of the thymidine kinase $(J 2 R)$ and the large subunit of ribonucleotide reductase (I4L) genes [11]. TG6002 expressing the fusion gene FCU1 ( $\triangle I 4 L \Delta J 2 R / F C U 1$ VACV) under the control of the p11K7.5 promoter was constructed and as previously described [11]. TG6002 was produced according to the Good Manufacturing Production on CEF, and virus stock was titrated on CEF by plaque assay.

\section{Laboratory dogs}

Seven adult healthy male Beagle dogs (Harlan Laboratories, Gannat, France) were used. The mean weight was $10.4 \pm 1.1 \mathrm{~kg}$ (mean \pm standard deviation). All dogs were acclimatized for 7 days before the start of the experiment and had regular inspections to detect any sanitary, or behavioral events. All dogs were under the care of a licensed veterinarian. The dogs were housed individually in inox-steel bar boxes with a resin soil substrate and a softwood chips litter. The room temperature was $19^{\circ} \mathrm{C}$ $\left(+/-2^{\circ} \mathrm{C}\right)$ with a humidity greater than $35 \%$, and the day/night cycle was 12:12 h. Dogs were fed twice daily with a certified commercial canine diet and given potable water ad libitum.

Dogs were not euthanized at the end of the study, but instead returned to the facility colony except in the case 
of grade 3 or grade 4 clinical, hematological or biochemical adverse events [57].

\section{Study design}

This study was conducted in accordance with European legislation and French regulations on the protection of animals used for scientific purposes (Directive 2010/63/EU, 2010; Code rural, 2018; Décret no. 2013-118, 2013) and complied to the recommendations of the "Charte nationale portant sur l'éthique en expérimentation animale" established by the "Comité National de Réflexion Ethique sur l'Expérimentation Animale" (CNREEA-Ministère de l'Enseignement Supérieur, de la Recherche et de l'InnovationMinistère de l'Agriculture et de l'Alimentation). The study protocol (n¹431_v2) was approved by the VetAgro Sup Ethical Committee (C2EA No. 18) and the Ministry of National Education, Higher Education and Research. Informed written consent to participate was required from the owners.

The first part of the study consisted of determining the MTD in four dogs, with each dog receiving a single different dose of TG6002 by intramuscular injection. The second part of the study assessed tolerability of several injections of TG6002 at the MTD, identified in the first part of the study, in combination with 5-FC administration. Intramuscular injections were chosen to mimic intratumoral route of administration in healthy dogs. The overall schedule of the study is shown in Fig. 5.

In the first part of the study, four dogs were randomized for single intramuscular injection of TG6002. The doses chosen in this study were similar to the doses administered in a clinical trial using TG6002 in human patients with advanced gastrointestinal tumors (NCT03724071) [58]. Dog 1 received $1 \times 10^{6} \mathrm{PFU} / \mathrm{kg}$, Dog 2 received $5 \times$ $10^{6} \mathrm{PFU} / \mathrm{kg}$, Dog 3 received $1 \times 10^{7} \mathrm{PFU} / \mathrm{kg}$ and Dog 4 received $5 \times 10^{7} \mathrm{PFU} / \mathrm{kg}$, diluted with $\mathrm{NaCl} 0.9 \%$. A single intramuscular (quadriceps or lumbar muscle) injection with a maximal volume of $0.5 \mathrm{ml} / \mathrm{kg}$ per site was performed in each dog. Multiple site injections were performed if the volume was over $0.5 \mathrm{ml} / \mathrm{kg}$. Injections were performed in a dedicated room of the laboratory animal facility and outside the room housing the dogs. To detect any side effects, injections were performed early in the morning to allow for observations and administrations between dogs were spaced by 7 days.

Dogs were evaluated once-a-day by a physical examination over 14days, after the injection of TG6002. Complete blood counts were performed using a Procyte Hematology analyzer (IDEXX Laboratory Inc., Westbrook, Maine, United States) before and 14 days after the injection of TG6002. Biochemistry analyses were performed

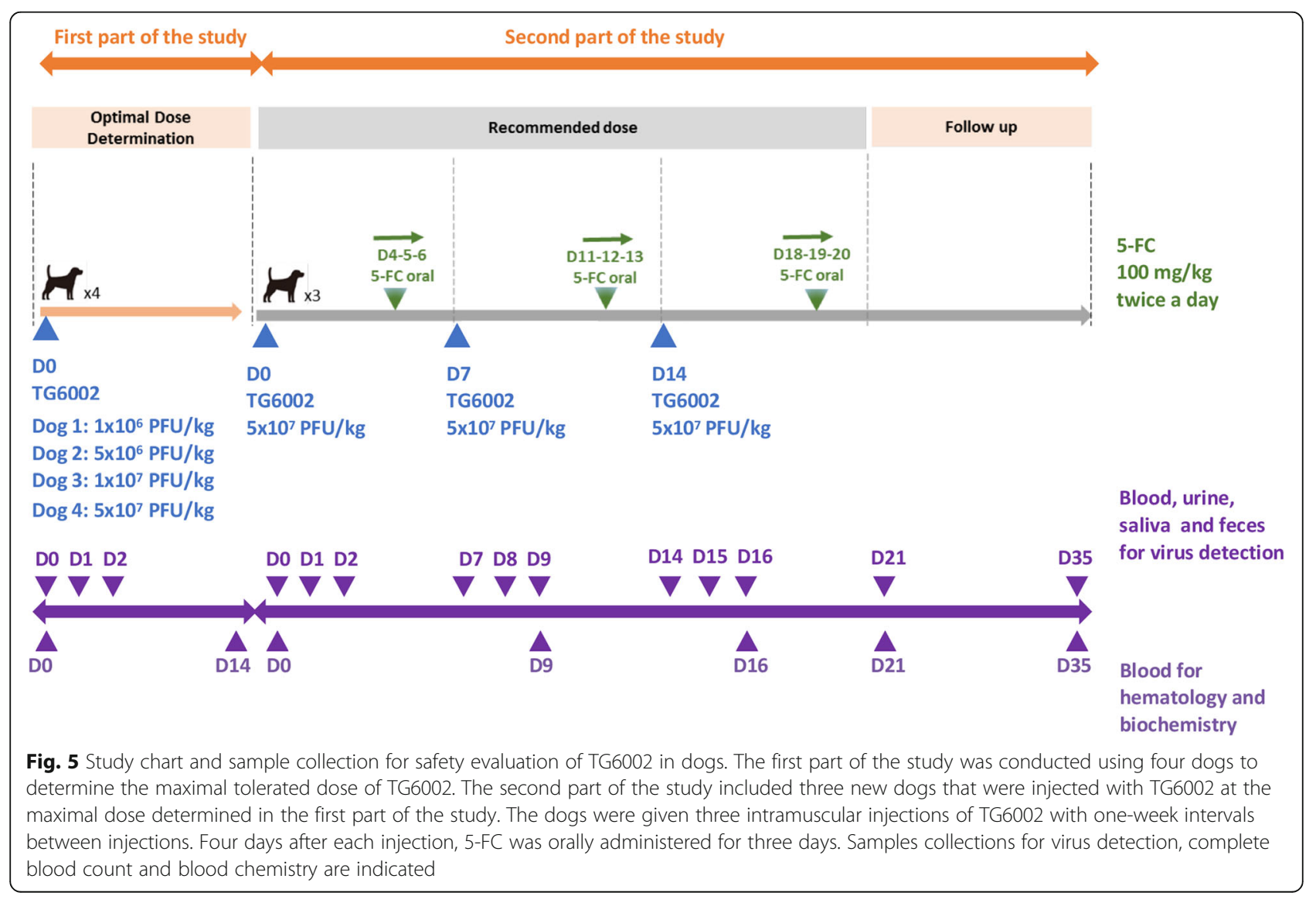


before and 14 days after the injection of TG6002 using a Catalyst Biochemistry analyzer (IDEXX Laboratory Inc., Westbrook, Maine, United States).

Body fluid samples (blood, saliva, urine and feces) were collected at days 0 (before virus injection), 1 and 2 and analysed to assess viral shedding. The MTD was defined as the highest dose of TG6002 that did not cause major side effects.

Three new dogs (Dog 5, Dog 6, Dog 7) were randomized for evaluating the tolerability to multiple injections combined with 5-FC. Dogs received three intramuscular injections of TG6002 at day 0, 7 and 14 at the defined MTD. Four days after each injection, 5-FC (Toronto Research Chemicals, North York, ON, Canada) was orally administered at a dose of $100 \mathrm{mg} / \mathrm{kg}$ twice a day for 3 days. Injections were performed in a dedicated room of the laboratory animal facility and outside the room housing the dogs. To detect any side effects, injections were performed early in the morning to allow for observations and administrations between dogs were spaced by 7 days.

Dogs were evaluated once-a-day by physical examination until 2 weeks after the last administration of 5-FC. Complete blood counts were performed at day 0, 9, 16, 21 and 35 using a Procyte Hematology analyzer (IDEXX Laboratory Inc., Westbrook, Maine, United States). Biochemistry analyses were performed at days 0,16 and 35 using a Catalyst Biochemistry analyzer (IDEXX Laboratory Inc., Westbrook, Maine, United States).

Bodily fluid samples (blood, saliva, urine and feces) were collected at day 0 (before virus injection), 1, 2, 7 (before second virus injection), 8, 9, 14 (before third virus injection), 15, 16, 21, and 35 and analysed to assess viral shedding.

\section{Adverse events}

Assessment of adverse events was performed according to the Veterinary Cooperative Oncology Group Common Terminology Criteria for Adverse Events v1.1 guidelines [57]. Adverse events were monitored throughout the study by daily physical examination, complete blood count and biochemistry analyses.

\section{Viral shedding}

Viral shedding was evaluated for both part of the study, on blood, saliva, urine and feces collected before and during the $48 \mathrm{~h}$ after each injection of TG6002. Additional evaluations were performed at day 21 and day 35 during the second part of the study (Fig. 5). Five milliliters of blood were collected in an EDTA tube, saliva samples were taken with buccal swabbing (Universal viral transport kit, Becton Dickinson, Franklin Lakes, New Jersey, United States), $5 \mathrm{ml}$ of urine were collected by ultrasonography guided vesical puncture and placed in a sterile Falcon tube, and one gram of feces was transferred to a sterile Falcon tube. All samples were stored at $-80^{\circ} \mathrm{C}$ until analysis. Viral shedding was evaluated by viral titration by plaque assay on CEF (for blood, saliva and urine) and by qPCR assay (for blood, saliva, urine and feces).

\section{Viral titration by plaque assay on CEF}

Viral titration by plaque assay was performed on CEF, each sample (blood, saliva, urine) was tested after dilution of $100 \mu$ l of sample in phosphate buffered saline supplemented with $1 \%$ fetal calf serum (FCS, Life Technologies, Carlsbad, California, United States) and 1\% cations (magnesium acetate $100 \mu \mathrm{g} / \mathrm{mL}$, calcium chloride $100 \mu \mathrm{g} / \mathrm{mL}$, Merck, Darmstadt, Germany) up to $1 \mathrm{ml}$. Diluted samples were sonicated three times for $5 \mathrm{~min}$ at room temperature and were titrated in triplicate on $\mathrm{CEF}$ by plaque assay as previously described [11].

\section{Viral quantification by qPCR assay}

DNA was extracted from $50 \mu \mathrm{l}$ of the whole blood, saliva, and urine samples using an automatic MagMax96 Deep Well (Life Technologies, Carlsbad, California, United States). Eight hundred milligrams of feces sample were diluted in $20 \mathrm{ml}$ of phosphate buffered saline, sonicated and centrifuged for $4 \mathrm{~min}$ at $1400 \mathrm{rpm}$. DNA extraction was performed on $50 \mu \mathrm{l}$ of sample using the MagMax 96 Viral RNA Isolation kit (Life Technologies, Carlsbad, California, United States) and the automatic MagMax96 Deep Well (Life Technologies, Carlsbad, California, United States). qPCR amplification was performed with the Multiplex Quantitect kit (Qiagen, Hilden, Germany) and was based on primers designed on VACV ITR region sequence (forward primer: CGATGA TGGAGTAATAAGTGGTAGGA, reverse primer: CACCGACCGATGATAAGATTTG, probe: ACTGAT TCCACCTCGGG). A standard curve was generated for absolute quantification by using the plasmid pTG15212 which contains the cloned VACV ITR sequence at both ends of the virus and located between position 6352 to 8180 (relative to Gene Bank sequence U94848) in the 5'region and position 169,909 to 171,737 in the 3 ' region of the viral genome. The ratio of plasmid/virus was two copies of pTG15212 for one copy of TG6002. Absolute quantification was performed by using a standard curve of pTG15212 plasmid. Positive controls were included with spiked samples of $10 \mu \mathrm{l}$ of the plasmid pTG15212 $(10,000$ copies) solution. All samples were run in triplicate. The limit of detection for analysis was 150 copies/ $\mathrm{ml}$ for whole blood, 300 copies/ml for urine and $36 \mathrm{cop}$ ies/mg for feces. It was not possible to define detection limits for saliva, since the amount of collected saliva was exceedingly low. 


\section{Histological and immunohistochemical analyses}

Histological analyses were performed on HematoxylinEosin-Saffron stained tissue sections. Immunohistochemical analyses were performed on kidney and liver samples using a rabbit anti-VACV polyclonal antibody (dilution 1/500) (B65101R, Meridian Life Science, Memphis, Tennessee). Immunohistochemical analyses were performed using a DXT automat (Ventana Medical Systems, Roche Diagnostics, Basel, Switzerland) with the streptavidin-biotin-peroxidase complex method with 3, 3 '-Diaminobenzidine as a substrate and hematoxylin counterstaining Formalin-fixed. As previously described, a canine mammary adenocarcinoma explant infected with TG6002 was used as positive control [13].

\section{Supplementary information}

Supplementary information accompanies this paper at https://doi.org/10 1186/s12917-020-02524-y.

Additional file 1. Biochemical analyses of dogs after single intramuscular injection of TG6002. No significant anomalies were noted. Bold numbers refer to values outside the reference interval.

Additional file 2. Biochemical analyses of dogs after three intramuscular injections of TG6002. No significant anomalies were noted. Bold numbers refer to values outside the reference interval.

Additional file 3. Detection of virus shedding by plaque assay after single intramuscular injection of TG6002. Infectious VACV was not detected in blood, urine and saliva samples by plaque assay method from dogs treated with escalating doses of TG6002. All samples were run in triplicate.

Additional file 4. Detection of virus shedding by plaque assay after three intramuscular injections of TG6002. Infectious VACV was not detected in blood, urine and saliva samples by plaque assay from dogs treated with three successive injections of TG6002 at $5 \times 10^{7} \mathrm{PFU} / \mathrm{kg}$. All samples were

Additional file 5. Detection of virus shedding by qPCR assay after a single intramuscular injection of TG6002. VACV DNA was not detected in blood, urine and saliva samples by GPCR assay from dogs treated with escalating doses of TG6002. All samples were run in triplicate.

Additional file 6 . Detection of virus shedding by qPCR assay after three intramuscular injections of TG6002. VACV DNA was not detected in blood, urine and saliva samples by GPCR assay from dogs treated with three successive injections of TG6002 at $5 \times 10^{7} \mathrm{PFU} / \mathrm{kg}$. All samples were run in triplicate.

\section{Abbreviations}

CEF: Chicken embryo fibroblast; FCS: Fetal calf serum; MTD: Maximal tolerated dose; TK: Thymidine kinase; RR: Ribonucleotide reductase; VACV: Vaccinia virus; 5-FC: 5-Fluorocytosine; 5-FU: 5-Fluorouracil

\section{Acknowledgments}

We would like to thank Caroline Schenkels and Thomas Donnelly for editorial assistance.

\section{Authors' contributions}

P.E., E.Q., J.M.B., and D.T. designed the study. J.B., J.F., V.N., and M.G. performed experiments. E.L. and S.C. performed histology and immunohistochemistry. J.B., J.F., E.Q., J.M.B., and P.E. supervised the study. J.B., C.M., B.K., and P.E. wrote the paper. All authors read and approved the final manuscript.

\section{Authors' information}

Not applicable

\section{Funding}

No funding was received for this study.

\section{Availability of data and materials}

The datasets used and/or analysed during the current study are available from the corresponding author on reasonable request.

\section{Ethics approval and consent to participate}

This study was conducted in accordance with European legislation and French regulations on the protection of animals used for scientific purposes (Directive 2010/63/EU, 2010; Code rural, 2018; Décret no. 2013-118, 2013) and complied to the recommendations of the "Charte nationale portant sur l'éthique en expérimentation animale" established by the "Comité National de Réflexion Ethique sur l'Expérimentation Animale" (CNREEA-Ministère de I'Enseignement Supérieur, de la Recherche et de I'Innovation-Ministère de l'Agriculture et de l'Alimentation). The study protocol (n¹431_v2) was approved by the VetAgro Sup Ethical Committee (C2EA No. 18) and Ministry of National Education, Higher Education and Research. Informed written consent to participate was required from the owners. Informed written consent was obtained from all dog owners.

\section{Consent for publication}

Not applicable.

\section{Competing interests}

J.B., V.N., M.G., S.C., J.F., J.M.B., E.Q., and P.E. were employees of Transgene SA when the work was performed. Transgene SA is a publicly traded French biopharmaceutical company, with Institut Merieux as the major shareholder. The authors declare no other competing interests. J.B. is recipient of an Industrial Training Convention for Research (CIFRE) doctoral fellowship (2017/ 0266)

\section{Author details}

${ }^{1}$ Transgene, Illkirch-Graffenstaden, France. ${ }^{2}$ UMR Virologie, INRAE, Ecole Nationale Vétérinaire d'Alfort, ANSES, Université Paris-Est, Maisons-Alfort, France. ${ }^{3}$ Department of Internal Medicine, Ecole Nationale Vétérinaire d'Alfort, Université Paris-Est, Maisons-Alfort, France. ${ }^{4}$ Anatomical Pathology Unit, Biopôle, Ecole Nationale Vétérinaire d'Alfort, Université Paris-Est, 94700 Maisons-Alfort, France. ${ }^{5}$ Oncovet Clinical Research, Loos, France.

Received: 2 May 2020 Accepted: 14 August 2020

Published online: 25 August 2020

\section{References}

1. Merlo DF, Rossi L, Pellegrino C, Ceppi M, Cardellino U, Capurro C, et al. Cancer incidence in pet dogs: findings of the animal tumor registry of Genoa, Italy. J Vet Intern Med. 2008;22:976-84.

2. Kelsey JL, Moore AS, Glickman T. Epidemiologic studies of risk factors for Cancer in pet dogs. Epidemiol Rev. 1998;20:204-17.

3. Miest TS, Cattaneo R. New viruses for cancer therapy: meeting clinical needs. Nat Rev Microbiol. 2014;12:23-34.

4. Harrington K, Freeman DJ, Kelly B, Harper J, Soria J-C. Optimizing oncolytic virotherapy in cancer treatment. Nat Rev Drug Discov. 2019;18:689-706.

5. Patil SS, Gentschev I, Nolte I, Ogilvie G, Szalay AA. Oncolytic virotherapy in veterinary medicine: current status and future prospects for canine patients. J Transl Med. 2012;10:3.

6. Sánchez D, Cesarman-Maus G, Amador-Molina A, Lizano M. Oncolytic viruses for canine Cancer treatment. Cancers. 2018;10.

7. Haddad D. Genetically engineered Vaccinia viruses as agents for Cancer treatment, imaging, and transgene delivery. Front Oncol. 2017;7:96.

8. Kirn DH, Thorne SH. Targeted and armed oncolytic poxviruses: a novel multi-mechanistic therapeutic class for cancer. Nat Rev Cancer. 2009;9:64-71.

9. Shen $Y$, Nemunaitis J. Fighting cancer with vaccinia virus: teaching new tricks to an old dog. Mol Ther J Am Soc Gene Ther. 2005;11:180-95.

10. Breitbach CJ, Burke J, Jonker D, Stephenson J, Haas AR, Chow LQM, et al. Intravenous delivery of a multi-mechanistic cancer-targeted oncolytic poxvirus in humans. Nature. 2011:477:99-102.

11. Foloppe J, Kempf J, Futin N, Kintz J, Cordier P, Pichon C, et al. The enhanced tumor specificity of TG6002, an armed Oncolytic Vaccinia virus deleted in two genes involved in nucleotide metabolism. Mol Ther Oncolytics. 2019;14:1-14. 
12. Erbs $P$, Regulier $E$, Kintz J, Leroy $P$, Poitevin $Y$, Exinger $F$, et al. In vivo cancer gene therapy by adenovirus-mediated transfer of a bifunctional yeast cytosine deaminase/uracil phosphoribosyltransferase fusion gene. Cancer Res. 2000;60:3813-22.

13. Béguin J, Foloppe J, Laloy E, Nourtier V, Farine I, Gantzer M, et al. Abstract 1446: characterization, evaluation and safety studies of the oncolytic Vaccinia virus TG6002 for canine cancer therapy. Atlanta: Immunology American Association for Cancer Research; 2019. p. 1446-6. https://doi.org/ 10.1158/1538-7445.AM2019-1446.

14. Rowell $\lrcorner$, McCarthy DO, Alvarez CE. Dog models of naturally occurring cancer. Trends Mol Med. 2011;17:380-8.

15. Regan D, Garcia K, Thamm D. Clinical, pathological, and ethical considerations for the conduct of clinical trials in dogs with naturally occurring Cancer: a comparative approach to accelerate translational drug development. ILAR J. 2018:59:99-110.

16. Paoloni M, Khanna C. Translation of new cancer treatments from pet dogs to humans. Nat Rev Cancer. 2008:8:147-56.

17. Buller RM, Palumbo GJ. Poxvirus pathogenesis. Microbiol Rev. 1991;55:80-122

18. Park B-H, Hwang T, Liu T-C, Sze DY, Kim J-S, Kwon H-C, et al. Use of a targeted oncolytic poxvirus, JX-594, in patients with refractory primary or metastatic liver cancer: a phase I trial. Lancet Oncol. 2008;9:533-42.

19. Heo J, Reid T, Ruo L, Breitbach CJ, Rose S, Bloomston M, et al. Randomized dose-finding clinical trial of oncolytic immunotherapeutic vaccinia JX-594 in liver cancer. Nat Med. 2013;19:329-36.

20. Downs-Canner S, Guo ZS, Ravindranathan R, Breitbach CJ, O'Malley ME, Jones HL, et al. Phase 1 study of intravenous Oncolytic poxvirus (VvDD) in patients with advanced solid cancers. Mol Ther J Am Soc Gene Ther. 2016; 24:1492-501.

21. Mell LK, Brumund KT, Daniels GA, Advani SJ, Zakeri K, Wright ME, et al. Phase I trial of intravenous Oncolytic Vaccinia virus (GL-ONC1) with Cisplatin and radiotherapy in patients with Locoregionally advanced head and neck carcinoma. Clin Cancer Res Off J Am Assoc Cancer Res. 2017;23:5696-702.

22. Kung C-H, Kuo S-C, Chen T-L, Weng W-S. Isolation of vaccinia JX594 from pustules following therapy for hepatocellular carcinoma. BMC Cancer. 2015; 15:704.

23. Biondo A, Pedersen JV, Karapanagiotou EM, Tunariu N, Mansfield D, Sassi S, et al. 1258 POSTER phase I clinical trial of a genetically modified Oncolytic Vaccinia virus GL-ONC1 with green fluorescent protein imaging. Eur J Cancer. 2011;47:S162.

24. Appel MJ, Paoletti E. Immune response to vaccinia virus and recombinant virus products in dogs. Am J Vet Res. 1988;49:1932-4.

25. Lederman E, Miramontes R, Openshaw J, Olson VA, Karem KL, Marcinak J, et al. Eczema vaccinatum resulting from the transmission of vaccinia virus from a smallpox vaccinee: an investigation of potential fomites in the home environment. Vaccine. 2009:27:375-7.

26. Abrahão JS, de Souza Trindade G, JMS F, Campos RK, Bonjardim CA, PCP F, et al. Long-lasting stability of Vaccinia virus strains in murine feces: implications for virus circulation and environmental maintenance. Arch Virol. 2009;154:1551-3.

27. Essbauer S, Meyer H, Porsch-Ozcürümez M, Pfeffer M. Long-lasting stability of vaccinia virus (orthopoxvirus) in food and environmental samples. Zoonoses Public Health. 2007:54:118-24.

28. Westberg S, Sadeghi A, Svensson E, Segall T, Dimopoulou M, Korsgren O, et al. Treatment efficacy and immune stimulation by AdCD40L gene therapy of spontaneous canine malignant melanoma. J Immunother. 2013; 36:350-8.

29. von Euler H, Sadeghi A, Carlsson B, Rivera P, Loskog A, Segall T, et al. Efficient adenovector CD40 ligand immunotherapy of canine malignant melanoma. J Immunother. 2008:31:377-84

30. Siddiqui F, Li C-Y, Larue SM, Poulson JM, Avery PR, Pruitt AF, et al. A phase I trial of hyperthermia-induced interleukin-12 gene therapy in spontaneously arising feline soft tissue sarcomas. Mol Cancer Ther. 2007;6:380-9.

31. Jourdier T-M, Moste C, Bonnet M-C, Delisle F, Tafani J-P, Devauchelle P, et al. Local immunotherapy of spontaneous feline fibrosarcomas using recombinant poxviruses expressing interleukin 2 (IL2). Gene Ther. 2003;10: 2126-32.

32. MacNeill AL, Weishaar KM, Séguin B, Powers BE. Safety of an Oncolytic Myxoma virus in dogs with soft tissue sarcoma. Viruses. 2018;10.

33. Hwang CC, Igase M, Sakurai M, Haraguchi T, Tani K, Itamoto K, et al. Oncolytic reovirus therapy: pilot study in dogs with spontaneously occurring tumours. Vet Comp Oncol. 2018;16:229-38.
34. Ilyinskaya GV, Mukhina EV, Soboleva AV, Matveeva OV, Chumakov PM. Oncolytic Sendai virus therapy of canine mast cell tumors (a pilot study). Front Vet Sci. 2018;5:116.

35. Naik S, Galyon GD, Jenks NJ, Steele MB, Miller AC, Allstadt SD, et al. Comparative oncology evaluation of intravenous recombinant Oncolytic vesicular stomatitis virus therapy in spontaneous canine Cancer. Mol Cancer Ther. 2018;17:316-26.

36. Cejalvo T, Perisé-Barrios AJ, Del Portillo I, Laborda E, Rodriguez-Milla MA, Cubillo I, et al. Remission of spontaneous canine tumors after systemic cellular Viroimmunotherapy. Cancer Res. 2018;78:4891-901.

37. Autio K, Knuuttila A, Kipar A, Pesonen S, Guse K, Parviainen S, et al. Safety and biodistribution of a double-deleted oncolytic vaccinia virus encoding CD40 ligand in laboratory beagles. Mol Ther Oncolytics. 2014;1:14002.

38. Autio KPM, Ruotsalainen JJ, Anttila MO, Niittykoski M, Waris M, Hemminki A, et al. Attenuated Semliki Forest virus for cancer treatment in dogs: safety assessment in two laboratory beagles. BMC Vet Res. 2015;11:170.

39. LeBlanc AK, Naik S, Galyon GD, Jenks N, Steele M, Peng K-W, et al. Safety studies on intravenous administration of oncolytic recombinant vesicular stomatitis virus in purpose-bred beagle dogs. Hum Gene Ther Clin Dev. 2013;24:174-81.

40. Smith BF, Curiel DT, Ternovoi W, Borovjagin AV, Baker HJ, Cox N, et al. Administration of a Conditionally Replicative Oncolytic Canine Adenovirus in Normal dogs. Cancer Biother Radiopharm. 2006;21:601-6.

41. Zeh HJ, Downs-Canner S, McCart JA, Guo ZS, Rao UNM, Ramalingam L, et al. First-in-man study of western reserve strain oncolytic vaccinia virus: safety, systemic spread, and antitumor activity. Mol Ther J Am Soc Gene Ther. 2015;23:202-14

42. Cripe TP, Ngo MC, Geller JI, Louis CU, Currier MA, Racadio JM, et al. Phase 1 study of intratumoral Pexa-Vec (JX-594), an oncolytic and immunotherapeutic vaccinia virus, in pediatric cancer patients. Mol Ther J Am Soc Gene Ther. 2015;23:602-8.

43. Cutler RE, Blair AD, Kelly MR. Flucytosine kinetics in subjects with normal and impaired renal function. Clin Pharmacol Ther. 1978;24:333-42.

44. Block ER, Bennett JE. Pharmacological studies with 5-fluorocytosine. Antimicrob Agents Chemother. 1972;1:476-82

45. Block ER, Bennett JE, Livoti LG, Klein WJ, MacGregor RR, Henderson L. Flucytosine and amphotericin B: hemodialysis effects on the plasma concentration and clearance. Studies in man. Ann Intern Med. 1974;80:613-7.

46. Vermes A, Guchelaar HJ, Dankert J. Flucytosine: a review of its pharmacology, clinical indications, pharmacokinetics, toxicity and drug interactions. J Antimicrob Chemother. 2000;46:171-9.

47. Malik R, Medeiros C, Wigney DI, Love DN. Suspected drug eruption in seven dogs during administration of flucytosine. Aust Vet J. 1996;74:285-8.

48. Panciera DL, Bevier D. Management of cryptococcosis and toxic epidermal necrolysis in a dog. J Am Vet Med Assoc. 1987;191:1125-7.

49. Ashbee HR, Barnes RA, Johnson EM, Richardson MD, Gorton R, Hope WW. Therapeutic drug monitoring (TDM) of antifungal agents: guidelines from the British Society for Medical Mycology. J Antimicrob Chemother. 2014;69: 1162-76.

50. Harris BE, Manning BW, Federle TW, Diasio RB. Conversion of 5fluorocytosine to 5 -fluorouracil by human intestinal microflora. Antimicrob Agents Chemother. 1986;29:44-8

51. Vermes A, Kuijper EJ, Guchelaar H-J, Dankert J. An in vitro study on the active conversion of flucytosine to fluorouracil by microorganisms in the human intestinal microflora. Chemotherapy. 2003;49:17-23.

52. Hwang T-H, Moon A, Burke J, Ribas A, Stephenson J, Breitbach CJ, et al. A mechanistic proof-of-concept clinical trial with JX-594, a targeted multimechanistic oncolytic poxvirus, in patients with metastatic melanoma. Mol Ther J Am Soc Gene Ther. 2011;19:1913-22.

53. Vail DM, Macewen EG. Spontaneously occurring tumors of companion animals as models for human Cancer. Cancer Investig. 2000;18:781-92.

54. Uva P, Aurisicchio L, Watters J, Loboda A, Kulkarni A, Castle J, et al. Comparative expression pathway analysis of human and canine mammary tumors. BMC Genomics. 2009;10:135.

55. Knapp DW, Glickman NW, Denicola DB, Bonney PL, Lin TL, Glickman LT. Naturally-occurring canine transitional cell carcinoma of the urinary bladder a relevant model of human invasive bladder cancer. Urol Oncol. 2000;5:47-59.

56. Knapp DW, Waters DJ. Naturally occurring cancer in pet dogs: important models for developing improved cancer therapy for humans. Mol Med Today. 1997;3:8-11. 
57. Veterinary cooperative oncology group. Common terminology criteria for adverse events (VCOG-CTCAE) following chemotherapy or biological antineoplastic therapy in dogs and cats v1.1. Vet Comp Oncol. 2016;14:417-46.

58. Clinical Trials.gov [Internet]. National Library of Medicine (US). Identifier NCT03724071, Study of TG6002 (W TK-RR-FCU1) in combination with 5-FC in patients with advanced gastrointestinal tumors; 2018 Oct 30. Available from: https://clinicaltrials.gov/ct2/show/NCT03724071.

\section{Publisher's Note}

Springer Nature remains neutral with regard to jurisdictional claims in published maps and institutional affiliations.

Ready to submit your research? Choose BMC and benefit from:

- fast, convenient online submission

- thorough peer review by experienced researchers in your field

- rapid publication on acceptance

- support for research data, including large and complex data types

- gold Open Access which fosters wider collaboration and increased citations

- maximum visibility for your research: over $100 \mathrm{M}$ website views per year

At $\mathrm{BMC}$, research is always in progress.

Learn more biomedcentral.com/submissions 